\title{
Structure of the ent-Copalyl Diphosphate Synthase PtmT2 from Streptomyces platensis CB00739, a Bacterial Type II Diterpene Synthase
}

\author{
Jeffrey D. Rudolf, ${ }^{1 *}$ Liao-Bin Dong, ${ }^{1 *}$ Hongnan Cao, ${ }^{2}$ Catherine Hatzos-Skintges, ${ }^{3}$ Jerzy \\ Osipiuk, ${ }^{3}$ Michael Endres, ${ }^{3}$ Chin-Yuan Chang, ${ }^{1}$ Ming Ma, ${ }^{1}$ Gyorgy Babnigg, ${ }^{3}$ Andrzej \\ Joachimiak, ${ }^{3}$ George N. Phillips, Jr., ${ }^{2}$ and Ben Shen ${ }^{1,4,5^{*}}$
}

${ }^{1}$ Department of Chemistry, The Scripps Research Institute, Jupiter, FL 33458, USA;

${ }^{2}$ Department of Biosciences, Rice University, Houston, TX $77005 ;{ }^{3}$ Midwest Center for Structural Genomics and Structural Biology Center, Biosciences Division, Argonne National Laboratory, Argonne, IL 60439; ${ }^{4}$ Department of Molecular Therapeutics, The Scripps Research Institute, Jupiter, FL 33458, USA; and ${ }^{5}$ Natural Products Library Initiative, The Scripps Research Institute, Jupiter, FL 33458, USA

${ }^{\ddagger}$ These authors contributed equally to this work.

"To whom correspondence should be addressed: The Scripps Research Institute, 130 Scripps Way, \#3A1, Jupiter, FL 33458; Tel: (561) 228-2456, Email: shenb@scripps.edu

\section{Supplementary Information (SI)}

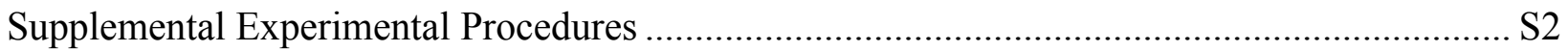

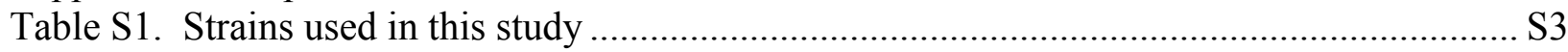

Table S2. Plasmids used in this study ................................................................................ S3

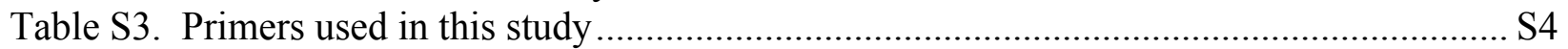

Table S4. Sequence and structure comparisons of selected terpene synthases with PtmT2....... S5

Table S5. Q-score matrix of $\beta \gamma$-domains of PtmT2 and other terpene synthases....................... S7

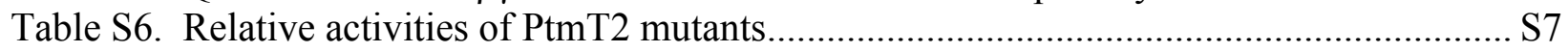

Figure S1. Enzymatic reactions of terpene synthases relevant to this work .............................. S8

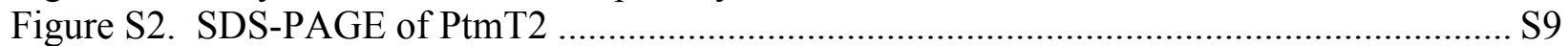

Figure S3. Size-exclusion chromatography of PtmT2 ……............................................. S10

Figure S4. PtmT2 reaction optimization ............................................................................ S11

Figure S5. Sequence alignment of functionally characterized type II DTSs from bacteria ...... S12

Figure S6. Kinetic characterization of five PtmT2 mutants ..................................................... S14

Figure S7. Phylogenetic analysis of PtmT2 with selected terpene synthases........................... S15

Figure S8. Electron density map for selected active site residues in PtmT2 …………........... S16

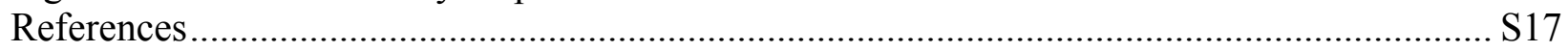




\section{Supplemental Experimental Procedures}

Synthesis of GGPP. GGPP was synthesized from trans, trans-farnesol according to previously reported procedures. ${ }^{1,2}$

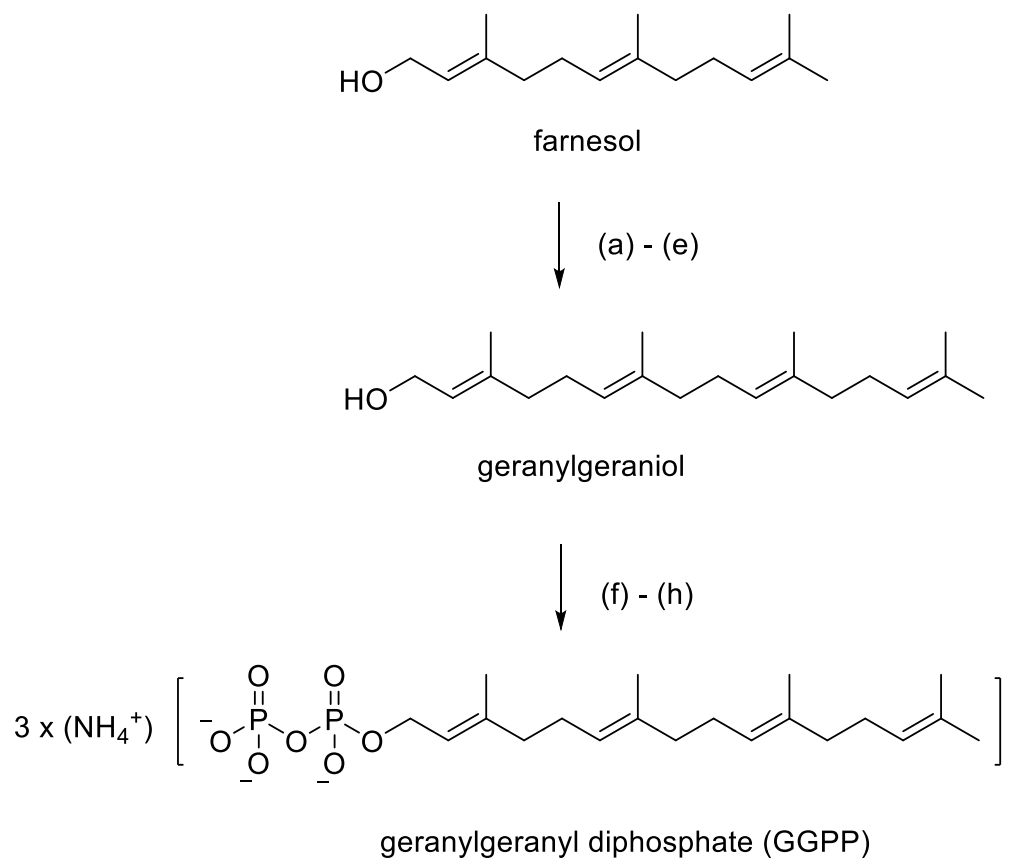

(a) $\mathrm{PBr}_{3}, \mathrm{Et}_{2} \mathrm{O}, 0^{\circ} \mathrm{C}, 2 \mathrm{~h}$; (b) ethyl acetoacetate, $\mathrm{NaOMe}, \mathrm{EtOH}$, dioxane, rt, 16 h; (c) $\mathrm{NaOH}, \mathrm{H}_{2} \mathrm{O}$, rt, $64 \mathrm{~h}$, then reflux $2 \mathrm{~h}$; (d) NaH, triethyl phosphonoacetate, iso-hexane, rt, $16 \mathrm{~h}$; (e) DIABL, toluene, $-78^{\circ} \mathrm{C}, 1 \mathrm{~h}$; (f) $\mathrm{PBr}_{3}, \mathrm{Et}_{2} \mathrm{O}, 0^{\circ} \mathrm{C}, 1 \mathrm{~h}$; (g) $\mathrm{HOPP}\left(\mathrm{NBu}_{4}\right)_{3}, \mathrm{CH}_{3} \mathrm{CN}$, rt, $2 \mathrm{~h}$; (h) Dowex AG $50 \mathrm{~W}-\mathrm{X} 8\left(\mathrm{NH}_{4}{ }^{+}\right.$form $)$

${ }^{1} \mathrm{H},{ }^{13} \mathrm{C}$, and ${ }^{31} \mathrm{P}$ NMR characterization of ent-copalyl diphosphate (ent-CPP) prepared by PtmT2-catalyzed synthesis from GGPP. ${ }^{1} \mathrm{H}$ NMR $\left(700 \mathrm{MHz}, \mathrm{D}_{2} \mathrm{O}\right) \delta: 5.40(1 \mathrm{H}, \mathrm{m}), 4.85(1 \mathrm{H}$, s), $4.58(1 \mathrm{H}, \mathrm{s}), 4.45(2 \mathrm{H}, \mathrm{m}), 2.37(1 \mathrm{H}, \mathrm{br} \mathrm{d}, J=11.2 \mathrm{~Hz}), 2.15(1 \mathrm{H}, \mathrm{m}), 1.98(1 \mathrm{H}, \mathrm{m}), 1.87(1 \mathrm{H}$, $\mathrm{m}), 1.74(2 \mathrm{H}, \mathrm{m}), 1.70(3 \mathrm{H}, \mathrm{s}), 1.63(2 \mathrm{H}, \mathrm{m}), 1.55(1 \mathrm{H}, \mathrm{m}), 1.45(2 \mathrm{H}, \mathrm{m}), 1.34(1 \mathrm{H}, \mathrm{d}, J=11.9$ $\mathrm{Hz}), 1.29(1 \mathrm{H}, \mathrm{m}), 1.16(1 \mathrm{H}, \mathrm{t}, J=11.2 \mathrm{~Hz}), 1.12(1 \mathrm{H}, \mathrm{d}, J=12.6 \mathrm{~Hz}), 1.02(1 \mathrm{H}, \mathrm{t}, J=11.2 \mathrm{~Hz})$, $0.83(3 \mathrm{H}, \mathrm{s}), 0.77(3 \mathrm{H}, \mathrm{s}), 0.65(3 \mathrm{H}, \mathrm{s}) ;{ }^{13} \mathrm{C}$ NMR $\left(175 \mathrm{MHz}, \mathrm{D}_{2} \mathrm{O}\right) \delta: 152.9,145.9,121.1(\mathrm{~d}, J=$ $5.3 \mathrm{~Hz}$ ), 107.4, 64.7 (d, $J=2.8 \mathrm{~Hz}), 57.6,56.7,43.5,41.1,40.4$, 39.8, 39.7, 34.8, 34.7, 26.0, 23.1, 23.0, 20.9, 17.5, 15.8; ${ }^{31} \mathrm{P}$ NMR (162 MHz, $\left.\mathrm{D}_{2} \mathrm{O}\right) \delta-7.72(1 \mathrm{P}, \mathrm{d}, J=18.0 \mathrm{~Hz}),-10.45(1 \mathrm{P}, \mathrm{d}, J=$ $18.0 \mathrm{~Hz})$. 
Table S1. Strains used in this study.

\begin{tabular}{lll}
\hline Strain & Genotype, Description & Source (Reference) \\
\hline E. coli DH5 $\alpha$ & E. coli host for general cloning & Life Technologies \\
E. coli BL21(DE3) & E. coli host for protein production & Life Technologies \\
E. coli BL21(DE3)-Gold & E. coli host for protein production & Stratagene/Agilent \\
S. platensis CB00739 & Wild-type PTM/PTN producer; used for & (3) \\
& $\begin{array}{l}\text { isolation of genomic DNA for PCR } \\
\text { amplification }\end{array}$ \\
\hline
\end{tabular}

Table S2. Plasmids used in this study.

\begin{tabular}{|c|c|c|}
\hline Plasmid & Description & Source (Reference) \\
\hline pBS3080 & $\begin{array}{l}\text { pRSFDuet-1 derived plasmid containing a } B s m \text { FI site } \\
\text { for ligation-independent cloning (LIC) and encodes a } \\
\text { TEV nrotease site after the N-terminal His }- \text {-tag }\end{array}$ & (4) \\
\hline pBS12043 & $\begin{array}{l}\text { pBS3080 harboring the full length } p t m T 2 \text {; used for } \\
\text { enzyme assays }\end{array}$ & This study \\
\hline pBS12044 & pBS12043-derived ptmT2 D128A mutant & This study \\
\hline pBS12045 & pBS12043-derived ptmT2 D128E mutant & This study \\
\hline pBS12046 & pBS12043-derived ptmT2 E133A mutant & This study \\
\hline pBS12047 & pBS12043-derived ptm T2 E133D mutant & This study \\
\hline pBS12048 & pBS12043-derived $p t m T 2$ D172A mutant & This study \\
\hline pBS12049 & pBS12043-derived ptmT2 D172E mutant & This study \\
\hline pBS12050 & pBS12043-derived $p t m T 2$ D128A-E133A mutant & This study \\
\hline pBS12051 & $\begin{array}{l}\text { pBS12043-derived ptmT2 D128A-E133A-D172A } \\
\text { mutant }\end{array}$ & This study \\
\hline pBS12052 & pBS12043-derived ptmT2 K193A mutant & This study \\
\hline pBS12053 & pBS12043-derived ptmT2 K193R mutant & This study \\
\hline pBS12054 & pBS12043-derived ptmT2 R350A mutant & This study \\
\hline pBS12055 & pBS12043-derived ptm T2 R350K mutant & This study \\
\hline pBS12056 & pBS12043-derived ptmT2 K402A mutant & This study \\
\hline pBS12057 & pBS12043-derived ptmT2 K402R mutant & This study \\
\hline pMCSG68 & $\begin{array}{l}\text { LIC plasmid that encodes a TEV protease site after the } \\
\text { N-terminal His }{ }^{-} \text {-and StrepII-tags, and the tRNA } \\
\text { genes, } \arg U \text { and } i l e X \text {, for rare codons }\end{array}$ & (5) \\
\hline pBS12058 & $\begin{array}{l}\text { pMCSG68 harboring truncated ptmT2 (residues } 9- \\
\text { 528); used for crystallography }\end{array}$ & This study \\
\hline
\end{tabular}


Table S3. Primers used in this study.

\begin{tabular}{|c|c|c|}
\hline Primer & Nucleotide Sequence $\left(5^{\prime}-3^{\prime}\right)^{a}$ & Function \\
\hline 739T2_F & $\begin{array}{l}\text { AAAACCTCTATTTCCAGTCGGTGCTCGAAGTT } \\
\text { CCCGCT }\end{array}$ & $\begin{array}{l}\text { ptmT2 amplification } \\
\text { for pBS3080 }\end{array}$ \\
\hline 739T2_R & $\begin{array}{l}\text { TACTTACTTAAATGTTATCAAGCACCTCCGGA } \\
\text { AGC }\end{array}$ & $\begin{array}{l}\text { ptmT2 amplification } \\
\text { for pBS3080 }\end{array}$ \\
\hline D128A F & GGTCCGGTGCCCGCCACCATCGGCGTC & Mutagenesis \\
\hline $\mathrm{D} 128 \mathrm{~A}^{-} \mathrm{R}$ & GACGCCGATGGTGGCGGGCACCGGACC & Mutagenesis \\
\hline $\mathrm{D} 128 \mathrm{E} \mathrm{F}$ & GGTCCGGTGCCCGAGACCATCGGCGTC & Mutagenesis \\
\hline $\mathrm{D} 128 \mathrm{E}^{-} \mathrm{R}$ & GACGCCGATGGTCTCGGGCACCGGACC & Mutagenesis \\
\hline E133A F & ACCATCGGCGTCGCGTTCGTCGCCCCG & Mutagenesis \\
\hline $\mathrm{E} 133 \mathrm{~A}^{-} \mathrm{R}$ & CGGGGCGACGAACGCGACGCCGATGGT & Mutagenesis \\
\hline $\mathrm{E} 133 \mathrm{D}^{-} \mathrm{F}$ & ACCATCGGCGTCGACTTCGTCGCCCCG & Mutagenesis \\
\hline $\mathrm{E} 133 \mathrm{D}^{-} \mathrm{R}$ & CGGGGCGACGAAGTCGACGCCGATGGT & Mutagenesis \\
\hline $\mathrm{D} 172 \mathrm{~A}^{-} \mathrm{F}$ & TCACCGGCGCCCGCCCTGGACGGTGCG & Mutagenesis \\
\hline $\mathrm{D} 172 \mathrm{~A}^{-} \mathrm{R}$ & CGCACCGTCCAGGGCGGGCGCCGGTGA & Mutagenesis \\
\hline D172E F & TCACCGGCGCCCGAGCTGGACGGTGCG & Mutagenesis \\
\hline D172E-R & CGCACCGTCCAGCTCGGGCGCCGGTGA & Mutagenesis \\
\hline K193A- F & CCGCTGCCGGAGGCGCTGTGGCACACC & Mutagenesis \\
\hline $\mathrm{K} 193 \mathrm{~A} \mathrm{R}$ & GGTGTGCCACAG $\overline{C G C} C T C C G G C A G C G G$ & Mutagenesis \\
\hline K193R F & CCGCTGCCGGAGAGGCTGTGGCACACC & Mutagenesis \\
\hline K193R R & GGTGTGCCACAGCCTCTCCGGCAGCGG & Mutagenesis \\
\hline $\mathrm{R} 350 \mathrm{~A}^{-} \mathrm{F}$ & TTCGGCGTCGAGGCCACCCCTTCGACC & Mutagenesis \\
\hline $\mathrm{R} 350 \mathrm{~A} \mathrm{R}$ & GGTCGAAGGGGTGGCCTCGACGCCGAA & Mutagenesis \\
\hline $\mathrm{R} 350 \mathrm{~K}^{-} \mathrm{F}$ & TTCGGCGTCGAGAAGACCCCTTCGACC & Mutagenesis \\
\hline $\mathrm{R} 350 \mathrm{~K} \mathrm{R}$ & GGTCGAAGGGGTCTTCTCGACGCCGAA & Mutagenesis \\
\hline $\mathrm{K} 402 \mathrm{~A}^{-} \mathrm{F}$ & AGCTGGATGGACGCGTGGCACGCCTCG & Mutagenesis \\
\hline $\mathrm{K} 402 \mathrm{~A}^{-} \mathrm{R}$ & CGAGGCGTGCCACGCGTCCATCCAGCT & Mutagenesis \\
\hline $\mathrm{K} 402 \mathrm{R} F$ & AGCTGGATGGACAGGTGGCACGCCTCG & Mutagenesis \\
\hline $\mathrm{K} 402 \mathrm{R}^{-} \mathrm{R}$ & CGAGGCGTGCCACCTGTCCATCCAGCT & Mutagenesis \\
\hline 739xtalT2_F & $\begin{array}{l}\text { TACTTCCAATCCAATGCCGTGCTCGAAGTTCC } \\
\text { CGCTCAGCCCAC }\end{array}$ & $\begin{array}{l}\text { ptmT2 amplification } \\
\text { pMCSG68 }\end{array}$ \\
\hline 739xtalT2_R & $\begin{array}{l}\text { TTATCCACTTCCAATGTTAAGCACCTCCGGAA } \\
\text { GCGGCGGACG }\end{array}$ & $\begin{array}{l}\text { ptmT2 amplification } \\
\text { pMCSG68 }\end{array}$ \\
\hline
\end{tabular}

${ }^{a}$ Nucleotides, corresponding to the residues that were mutated, are underlined. 
Table S4. Sequence and structure comparisons of selected terpene synthases with PtmT2 (AIW55555).

\begin{tabular}{|c|c|c|c|c|c|c|c|c|}
\hline $\begin{array}{c}\text { Protein } \\
\text { (NCBI Accession) }\end{array}$ & Organism & $\begin{array}{c}\text { Coverage } \\
(\%)^{a}\end{array}$ & $\begin{array}{l}\text { Identity } \\
(\%)^{a}\end{array}$ & $\begin{array}{l}\text { Similarity } \\
(\%)^{a}\end{array}$ & PDB ID & Architecture & Ligand & $\begin{array}{c}\text { Ca rmsd }(\AA) / \\
\text { Q-score }^{b}\end{array}$ \\
\hline \multicolumn{9}{|l|}{ Bacterial DTS } \\
\hline $\begin{array}{c}\text { PtnT2 } \\
(\text { ADD83015) }\end{array}$ & $\begin{array}{c}\text { Streptomyces platensis } \\
\text { MA7339 }\end{array}$ & 100 & 97 & 97 & - & - & - & - \\
\hline $\begin{array}{l}\text { entCPPS-KO3988 } \\
\text { (BAD86797) }\end{array}$ & Streptomyces sp. KO-3988 & 95 & 46 & 58 & - & - & - & - \\
\hline $\begin{array}{c}\text { BjCPS } \\
\left(\mathrm{NP}_{-} 768789\right)\end{array}$ & $\begin{array}{c}\text { Bradyrhizobium japonicum } \\
\text { USDA } 110\end{array}$ & 94 & 31 & 41 & - & - & - & - \\
\hline $\begin{array}{c}\text { Sare } \\
(\text { ABV97191) }\end{array}$ & Salinispora arenicola CNS-205 & 98 & 44 & 55 & - & - & - & - \\
\hline $\begin{array}{c}\text { CldB } \\
(\text { BAR97451) }\end{array}$ & Streptomyces cyslabdanicus & 94 & 42 & 52 & - & - & - & - \\
\hline $\begin{array}{c}\text { RmnB } \\
\text { (BAR97461) }\end{array}$ & Streptomyces anulatus & 94 & 41 & 50 & - & - & - & - \\
\hline $\begin{array}{l}\text { SCLAV_p0490 } \\
\text { (EFG03980) }\end{array}$ & $\begin{array}{c}\text { Streptomyces clavuligerus } \\
\text { ATCC } 27064\end{array}$ & 97 & 39 & 49 & - & - & - & - \\
\hline $\begin{array}{c}\text { CYC1 } \\
\text { (BAB39206) }\end{array}$ & Kitasatospora griseola & 96 & 33 & 47 & - & - & - & - \\
\hline $\begin{array}{c}\text { Rv3377c } \\
(\mathrm{NP} 217894)\end{array}$ & $\begin{array}{c}\text { Mycobacterium tuberculosis } \\
\text { H37Rv }\end{array}$ & 92 & 29 & 42 & - & - & - & - \\
\hline $\begin{array}{c}\text { Bra4 } \\
(\mathrm{BAG} 16278)\end{array}$ & Nocardia terpenica & 83 & 36 & 45 & - & - & - & - \\
\hline $\begin{array}{c}\text { PlaT2 } \\
\text { (ABB69743) }\end{array}$ & Streptomyces sp. Tu6071 & 45 & 34 & 43 & - & - & - & - \\
\hline \multicolumn{9}{|l|}{ Plant DTS } \\
\hline \multirow[t]{2}{*}{$\begin{array}{c}A t \mathrm{CPS} \\
\left(\mathrm{NP} \_192187\right)\end{array}$} & \multirow[t]{2}{*}{ Arabidopsis thaliana } & \multirow[t]{2}{*}{69} & \multirow[t]{2}{*}{27} & \multirow[t]{2}{*}{40} & $4 \mathrm{LIX}^{6}$ & \multirow[t]{2}{*}{$\alpha \beta \gamma$} & AzaGGSPP & $2.72 / 0.18$ \\
\hline & & & & & $3 \mathrm{PYB}^{7}$ & & AzaCPP & $2.86 / 0.17$ \\
\hline $\begin{array}{c}A g A S \\
(\mathrm{Q} 38710)\end{array}$ & Abies grandis & 65 & 25 & 38 & $3 \mathrm{~S} 9 \mathrm{~V}^{8}$ & $\alpha \beta \gamma$ & Uncomplexed & $2.70 / 0.16$ \\
\hline $\begin{array}{l}\text { synCPS } \\
\text { (Q0JF02) }\end{array}$ & Oryza sativa & 75 & 27 & 39 & - & - & - & - \\
\hline \multirow[t]{2}{*}{$\begin{array}{l}\text { TbTS } \\
(\mathrm{Q} 41594)\end{array}$} & \multirow[t]{2}{*}{ Taxus brevifolia } & \multirow[t]{2}{*}{72} & \multirow[t]{2}{*}{24} & \multirow[t]{2}{*}{38} & $3 \mathrm{P} 5 \mathrm{P}^{9}$ & \multirow[t]{2}{*}{$\alpha \beta \gamma$} & AzaCPP & $3.02 / 0.13$ \\
\hline & & & & & $3 \mathrm{P} 5 \mathrm{R}^{9}$ & & 2-F-GGPP & $3.05 / 0.13$ \\
\hline
\end{tabular}


Table S4 cont. Sequence and structure comparisons of selected terpene synthases with PtmT2.

\begin{tabular}{|c|c|c|c|c|c|c|c|c|}
\hline $\begin{array}{c}\text { Protein } \\
\text { (NCBI Accession) } \\
\end{array}$ & Organism & $\begin{array}{c}\text { Coverage } \\
(\%)^{a}\end{array}$ & $\begin{array}{l}\text { Identity } \\
(\%)^{a}\end{array}$ & $\begin{array}{l}\text { Similarity } \\
(\%)^{a}\end{array}$ & PDB ID & Architecture & Ligand & $\begin{array}{c}\text { Ca rmsd }(\AA) / \\
\text { Q-score }^{b}\end{array}$ \\
\hline \multicolumn{9}{|l|}{ TTS } \\
\hline \multirow{2}{*}{$\begin{array}{c}\text { SHC } \\
(\mathrm{P} 33247)\end{array}$} & \multirow[t]{2}{*}{ Alicyclobacillus acidocaldarius } & \multirow[t]{2}{*}{46} & \multirow[t]{2}{*}{33} & \multirow[t]{2}{*}{43} & $1 \mathrm{UMP}^{10}$ & \multirow[t]{2}{*}{$\beta \gamma$} & Azasqualene & $2.82 / 0.22$ \\
\hline & & & & & $2 \mathrm{SQC}^{11}$ & & Uncomplexed & $2.80 / 0.22$ \\
\hline $\begin{array}{c}\text { hOSC } \\
\text { (P48449) }\end{array}$ & Homo sapiens & 45 & 30 & 42 & $1 \mathrm{~W} 6 \mathrm{~K}^{12}$ & $\beta \gamma$ & Lanosterol & $2.95 / 0.18$ \\
\hline \multicolumn{9}{|l|}{ Other TS } \\
\hline \multirow[t]{2}{*}{$\begin{array}{l}A g B I S \\
(\mathrm{O} 81086)\end{array}$} & \multirow[t]{2}{*}{ Abies grandis } & \multirow[t]{2}{*}{73} & \multirow[t]{2}{*}{24} & \multirow[t]{2}{*}{39} & $3 \mathrm{SAE}^{13}$ & \multirow[t]{2}{*}{$\alpha \beta \gamma$} & FSPP & $3.03 / 0.15$ \\
\hline & & & & & $3 \mathrm{SDQ}^{13}$ & & Uncomplexed & $2.89 / 0.15$ \\
\hline \multirow{2}{*}{$\begin{array}{c}\text { LS } \\
\text { (AAC37366) }\end{array}$} & \multirow[t]{2}{*}{ Mentha spicata } & \multirow[t]{2}{*}{15} & \multirow[t]{2}{*}{24} & \multirow[t]{2}{*}{40} & $2 \mathrm{ONG}^{14}$ & \multirow[t]{2}{*}{$\alpha \beta$} & 2-F-GPP & $3.53 / 0.036$ \\
\hline & & & & & $2 \mathrm{ONH}^{14}$ & & 2-F-LPP & $3.06 / 0.037$ \\
\hline \multirow[t]{2}{*}{$\begin{array}{c}\text { BPPS } \\
(\text { O81192) }\end{array}$} & \multirow[t]{2}{*}{ Salvia officinalis } & \multirow[t]{2}{*}{7} & \multirow[t]{2}{*}{30} & \multirow[t]{2}{*}{37} & $1 \mathrm{~N} 21^{15}$ & \multirow[t]{2}{*}{$\alpha \beta$} & AzaGPP & $3.32 / 0.037$ \\
\hline & & & & & $1 \mathrm{~N} 1 \mathrm{~B}^{15}$ & & Uncomplexed & $3.83 / 0.038$ \\
\hline
\end{tabular}

\footnotetext{
${ }^{a}$ Sequence comparisons (coverage, identity, and similarity) with calculated using BLASTp ${ }^{16}$ and PtmT2 (AIW55555) as the query sequence.
}

${ }^{b} \mathrm{C} \alpha$ rmsd values and Q-scores were calculated using PDBeFold ${ }^{17}$ and chain A of each PDB entry. 
Table S5. Q-score matrix of $\beta \gamma$-domains of PtmT2 and other terpene synthases.

\begin{tabular}{c|ccccccc}
\hline & PtmT2 & AtCPS & AgAS & TbTS & AgBIS & SHC & hOSC \\
& (5BP8) & (4LIX) & $(3 \mathrm{~S} 9 \mathrm{~V})$ & $(3 \mathrm{P} 5 \mathrm{P})$ & $(3 \mathrm{SAE})$ & $(1 \mathrm{UMP})$ & $(1 \mathrm{~W} 6 \mathrm{~K})$ \\
\hline PtmT2 (5BP8) & - & 0.28 & 0.27 & 0.26 & 0.25 & 0.22 & 0.18 \\
AtCPS (4LIX) & & - & 0.82 & 0.68 & 0.59 & 0.17 & 0.14 \\
AgAS (3S9V) & & & - & 0.76 & 0.64 & 0.15 & 0.12 \\
TbTS (3P5P) & & & & - & 0.62 & 0.16 & 0.13 \\
AgBIS (3SAE) & & & & & - & 0.13 & 0.098 \\
SHC (1UMP) & & & & & & - & 0.5 \\
hOSC (1W6K) & & & & & & & - \\
\hline
\end{tabular}

Table S6. Activities $^{a}$ of PtmT2 mutants.

\begin{tabular}{lcc}
\hline PtmT2 Variant & ${\text { Rate }\left(\mathrm{s}^{-1}\right)^{b}}^{b}$ & Relative Rate $(\%)^{c}$ \\
\hline WT & $1.1 \pm 0.1$ & $100 \pm 6$ \\
D128A & $(3.6 \pm 0.3) \times 10^{-2}$ & $3.3 \pm 0.3$ \\
D128E & $(3.2 \pm 0.1) \times 10^{-1}$ & $29 \pm 1$ \\
E133A & $(9.8 \pm 0.3) \times 10^{-2}$ & $9.0 \pm 0.3$ \\
E133D & $(7.4 \pm 0.1) \times 10^{-2}$ & $6.8 \pm 0.6$ \\
D172A & $(7.8 \pm 0.8) \times 10^{-1}$ & $71 \pm 7$ \\
D172E & $1.2 \pm 0.1$ & $108 \pm 7$ \\
D128A E133A & $(6.7 \pm 0.3) \times 10^{-2}$ & $6.1 \pm 0.3$ \\
D128A E133A D172A & $(6.1 \pm 0.7) \times 10^{-2}$ & $5.6 \pm 0.7$ \\
K193A & $(9.3 \pm 0.1) \times 10^{-2}$ & $8.5 \pm 1.2$ \\
K193R & $(3.7 \pm 0.5) \times 10^{-1}$ & $34 \pm 5$ \\
R350A & $(4.6 \pm 0.2) \times 10^{-1}$ & $42 \pm 2$ \\
R350K & $1.1 \pm 0.1$ & $100 \pm 4$ \\
K402A & n.d. ${ }^{d}$ & - \\
K402R & $(2.7 \pm 0.1) \times 10^{-2}$ & $2.5 \pm 0.1$ \\
\hline
\end{tabular}

${ }^{a}$ Performed in triplicate with standard deviations listed

${ }^{b}$ At $50 \mu \mathrm{M}, \sim K_{\mathrm{m}}$ (GGPP) for wild-type (WT)

${ }^{c}$ Compared to WT

${ }^{d}$ n.d., no activity detected 
Figure S1. Enzymatic reactions of terpene synthases relevant to this work.
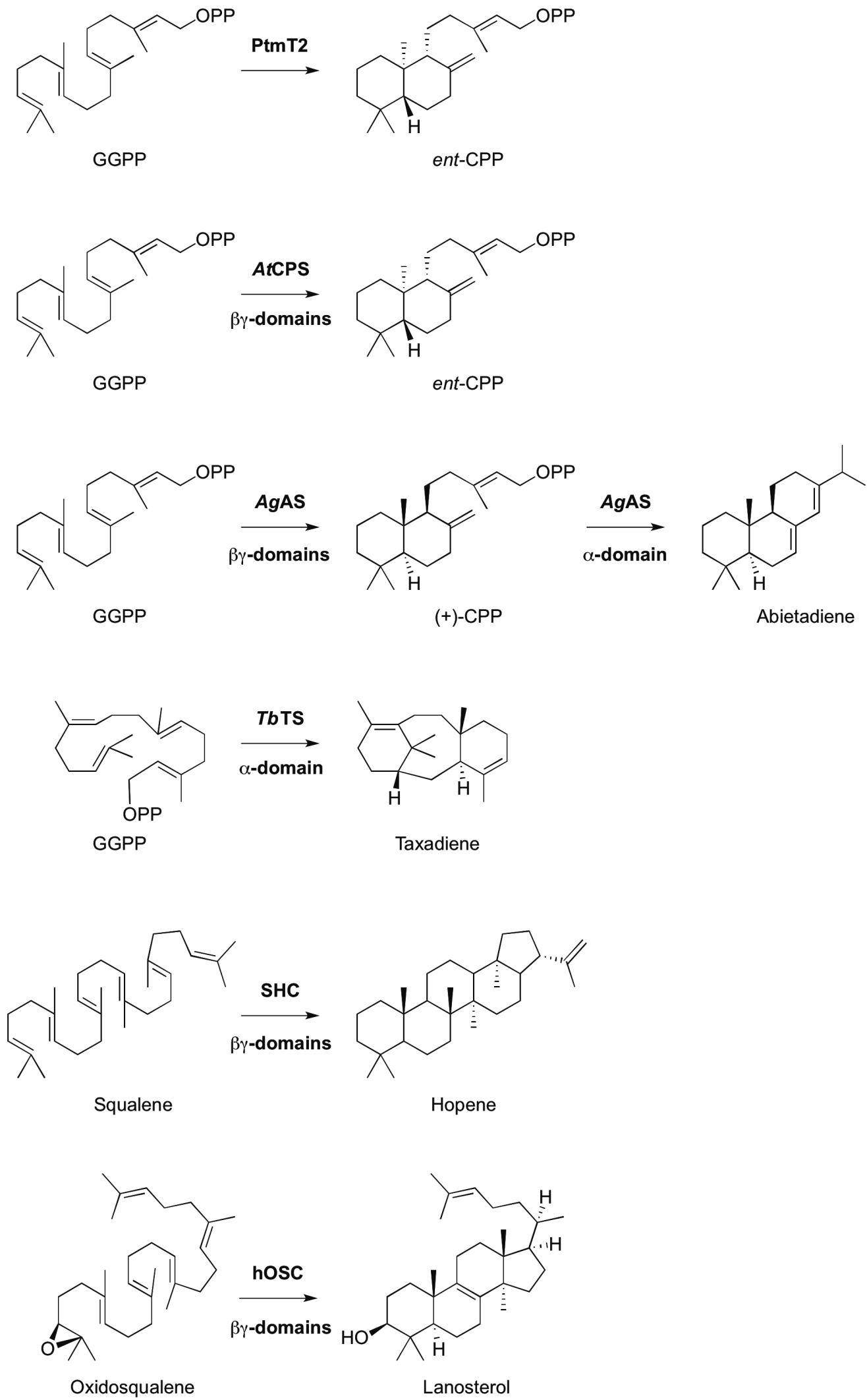
Figure S2. SDS-PAGE of PtmT2. Lanes M, Precision Plus Protein standards (Bio-Rad), lanes 1 and 3, total cells after ptmT2 expression; lanes 2 and 4, soluble lysate; lanes 5 and 7, purified PtmT2 before TEV protease cleavage; lanes 6 and 8, purified PtmT2 after TEV protease cleavage. Lanes 3, 4, 7, and 8 are of truncated PtmT2, residues $9-528$. The calculated MWs for uncut and TEV protease-cleaved PtmT2 are $\sim 58.1$ and $\sim 54.5 \mathrm{kDa}$, respectively. Lanes 1, 2, 5, and 6 are of another truncated PtmT2 construct, residues $5-528$ that is not discussed in this study.

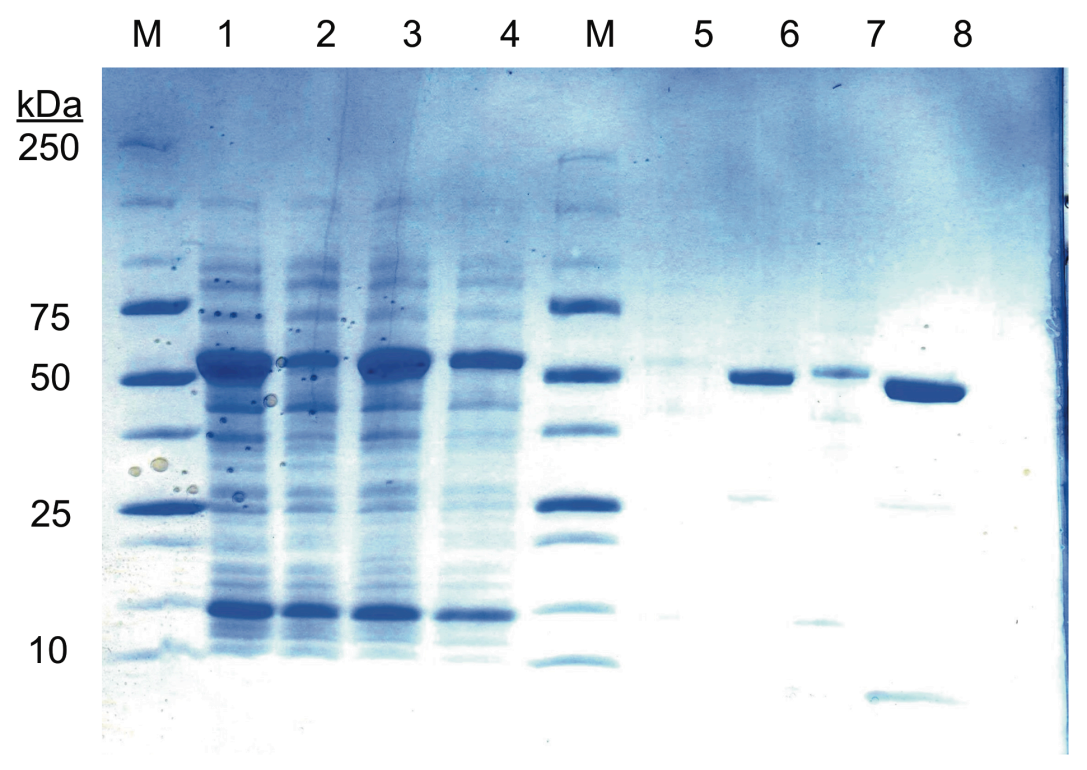


Figure S3. Size-exclusion chromatography of PtmT2. Ribonuclease A (13.7 kDa), carbonic anhydrase $(29 \mathrm{kDa})$, ovalbumin $(44 \mathrm{kDa})$, conalbumin $(75 \mathrm{kDa})$, and aldolase $(158 \mathrm{kDa})$ were used to construct the standard curve (black diamonds). The calibration curve of $\mathrm{K}_{\mathrm{av}}$ versus $\log (\mathrm{MW})$ was prepared using the equation $\mathrm{K}_{\mathrm{av}}=\mathrm{V}_{\mathrm{e}}-\mathrm{V}_{\mathrm{o}} /\left(\mathrm{V}_{\mathrm{t}}-\mathrm{V}_{\mathrm{o}}\right)$, where $\mathrm{V}_{\mathrm{e}}, \mathrm{V}_{\mathrm{o}}$, and $\mathrm{V}_{\mathrm{t}}$ is the elution volume, column void volume, and total bed volume, respectively. PtmT2 (red square) eluted at a retention volume of $6.00 \mathrm{~mL}$, correlating to a $\mathrm{MW}$ of $57.5 \mathrm{kDa}$. The calculated $\mathrm{MW}$ for TEV protease-cleaved PtmT2 is $\sim 54.5 \mathrm{kDa}$.

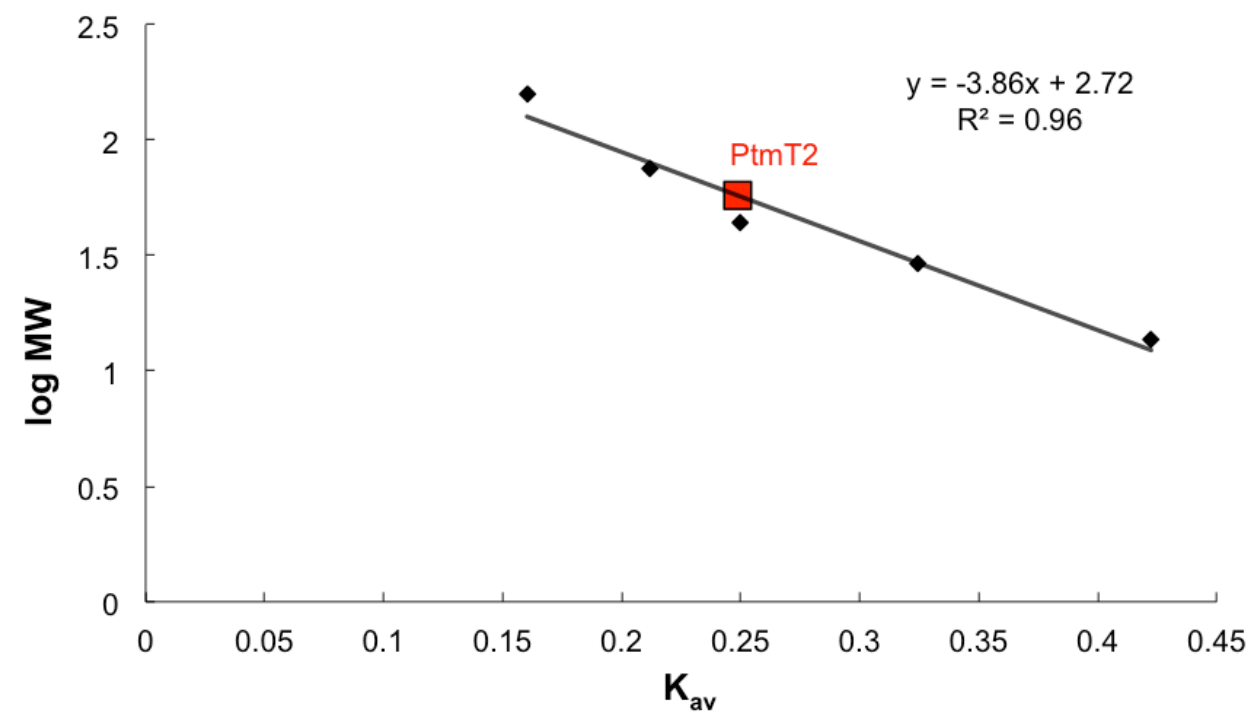


Figure S4. PtmT2 reaction optimization. (A) Buffer and $\mathrm{pH}$ optimization. The reaction velocity $\left(\mu \mathrm{M} \mathrm{min}^{-1}\right)$ of PtmT2 was calculated in the presence of tris, MOPS, or citrate buffer with a total $\mathrm{pH}$ range of 4.0 - 9.0. (B) Divalent metal ion optimization. The relative activities of the PtmT2 reaction was calculated using $\mathrm{MgCl}_{2}$ as $100 \% . \mathrm{CoCl}_{2},(66.5 \%), \mathrm{ZnCl}_{2}(58.8 \%)$, and $\mathrm{NiCl}_{2}$ (26.3\%) all showed product, ent-CPP, formation; no ent-CPP was observed in the absence of metal ions, or the presence of $\mathrm{MnCl}_{2}$ or EDTA. $\mathrm{MnCl}_{2}$ produced a floccule-like suspension.

A

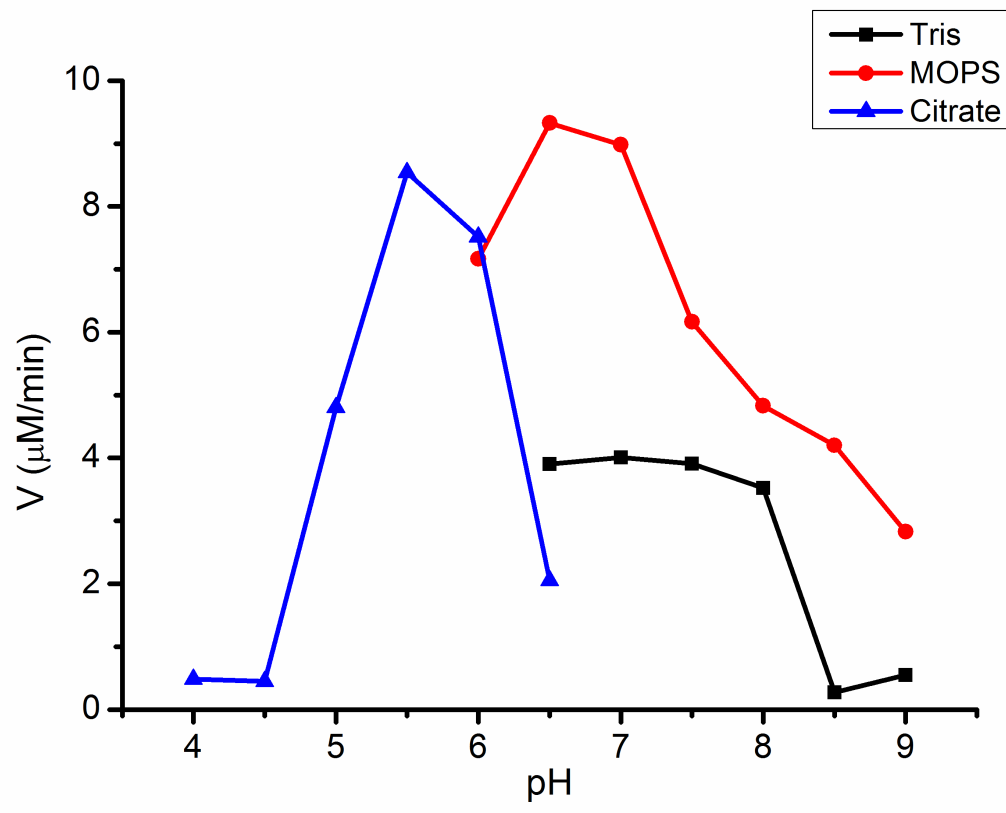

B

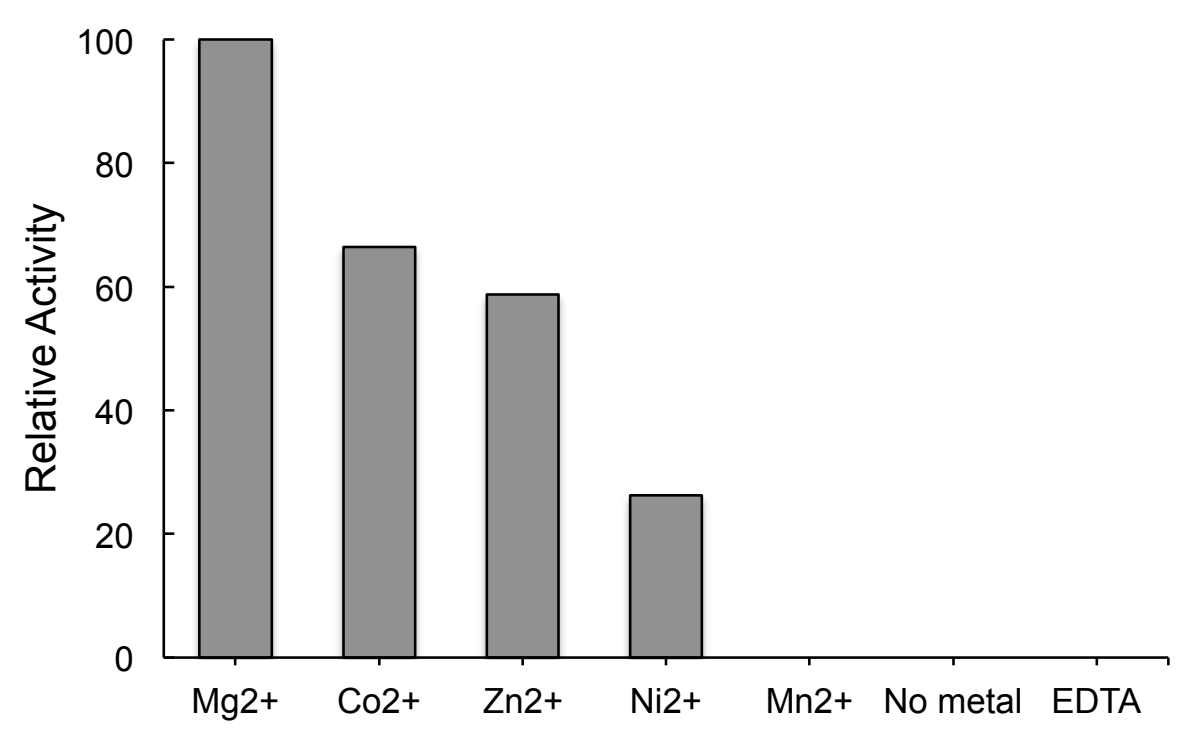


Figure S5. Sequence alignment of functionally characterized type II DTSs from bacteria. Aligned residues are colored based on the level of conservation (red box with white character shows strict identity, red character similarity, and blue frame similarity across groups). The corresponding secondary structure of PtmT2 (739T2, PDB entry 5BP8) is depicted above the sequence alignment. The $\mathrm{D}^{311} \mathrm{XDD}$ motif and His359 are with shown with black asterisks; the residues targeted for mutation, including the $\mathrm{D}^{128} \mathrm{xxxE}$ motif are shown with red asterisks. The alignment was created with MUSCLE ${ }^{18}$ and rendered with ESPript 3.0. ${ }^{19}$
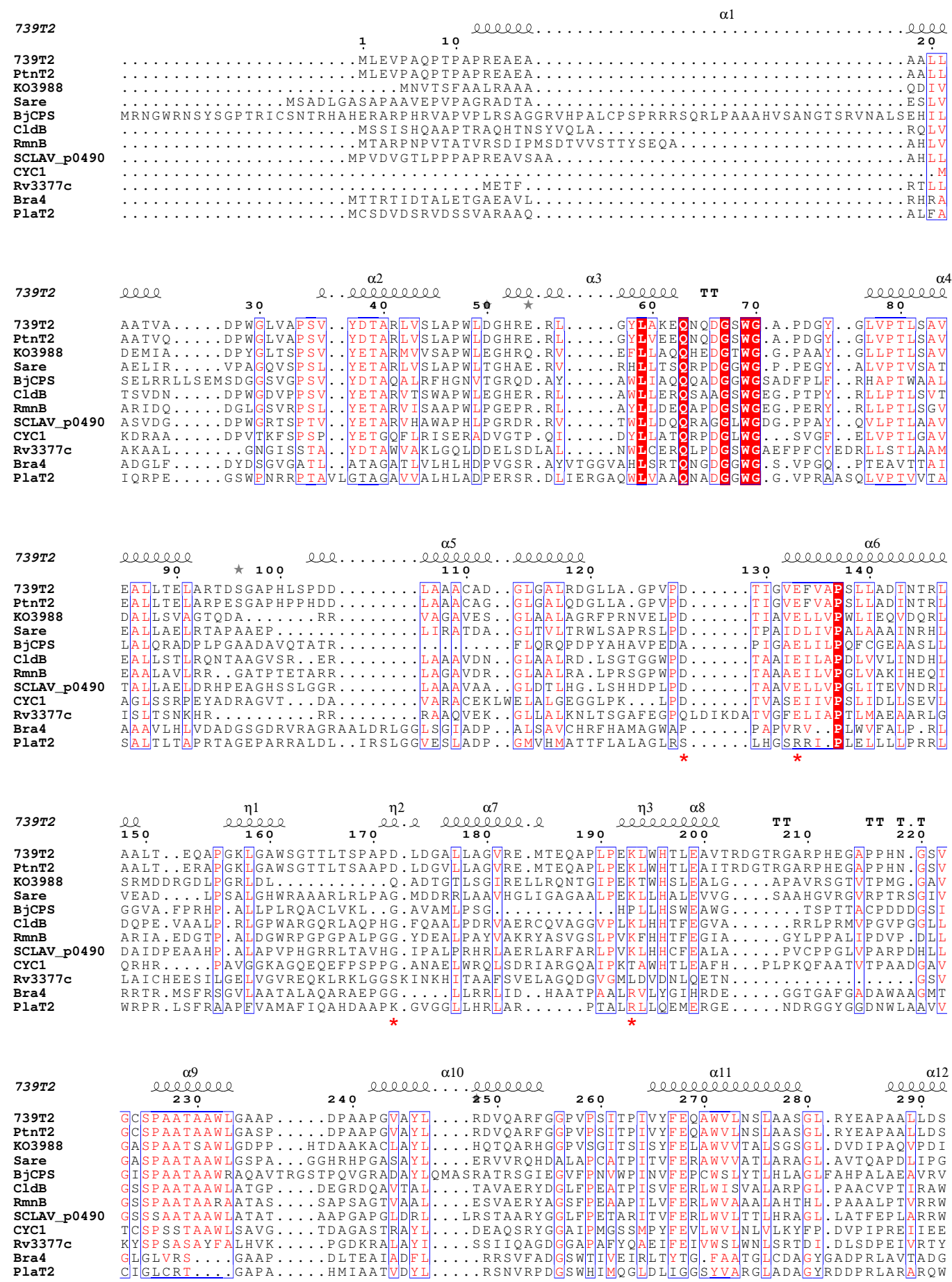
Figure S5 cont. Sequence alignment of functionally characterized type II DTSs from bacteria.

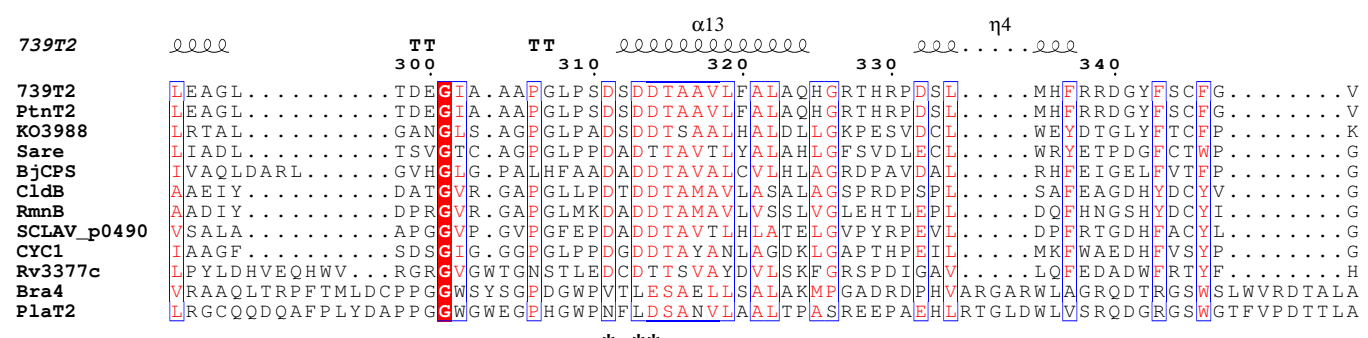

$$
\text { *** }
$$
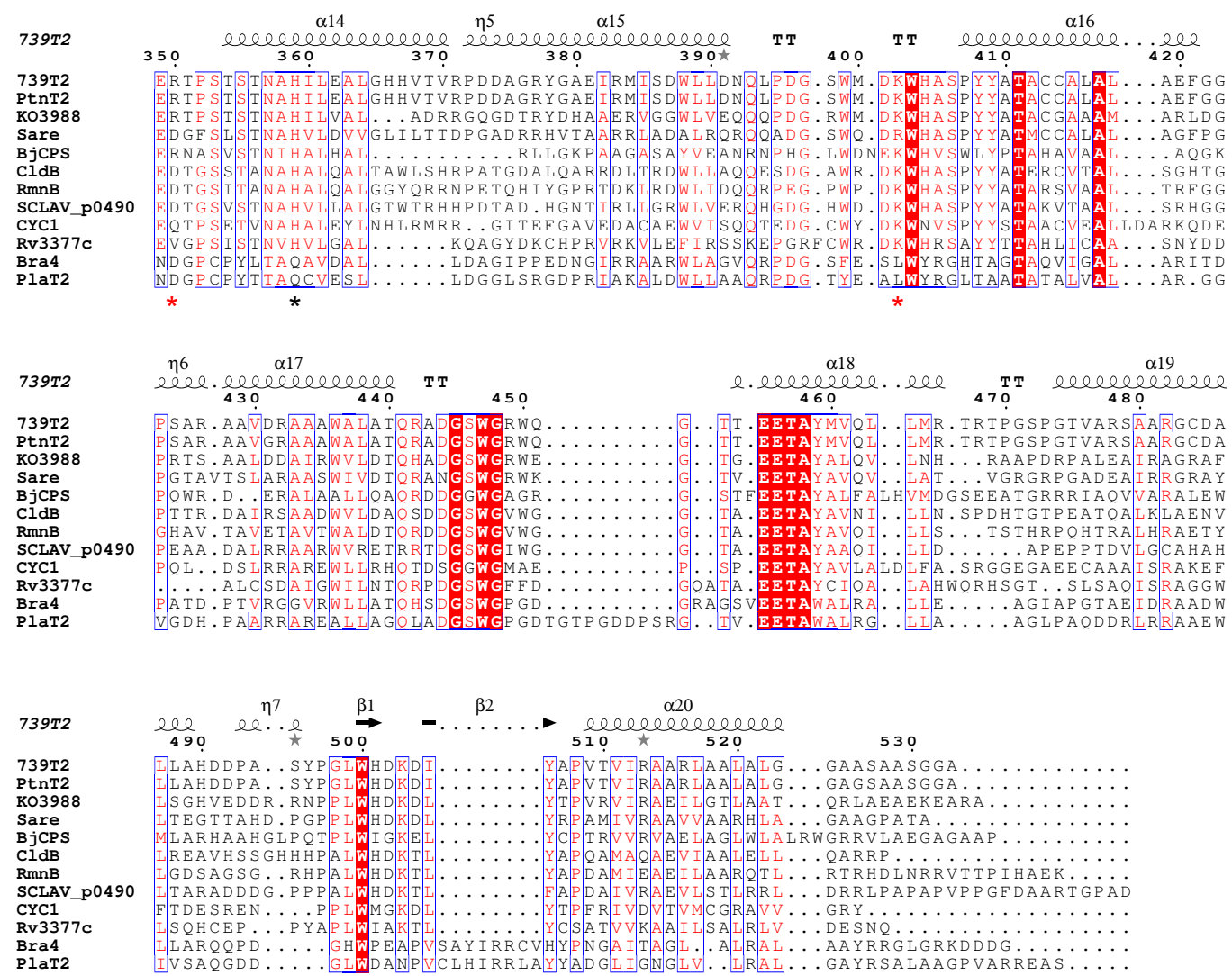
Figure S6. Kinetic analysis of five PtmT2 mutants. (A) D128A; (B) E133A; (C) D128A-E133A; (D) K193A; (E) D128E; (G) Kinetic parameters were calculated for three mutants (A-C) by fitting the data to the substrate inhibition model and equation in (F) (GraphPad Prism 6.07). For the remaining two mutants ( $\mathrm{D}$ and $\mathrm{E}$ ), the fit was unable to calculate meaningful parameters. Assays were performed as described for WT, but with varying GGPP concentrations.

A

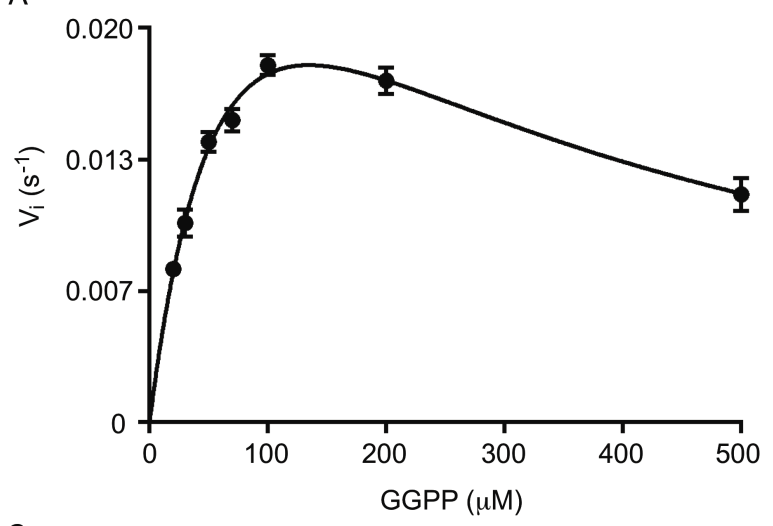

C

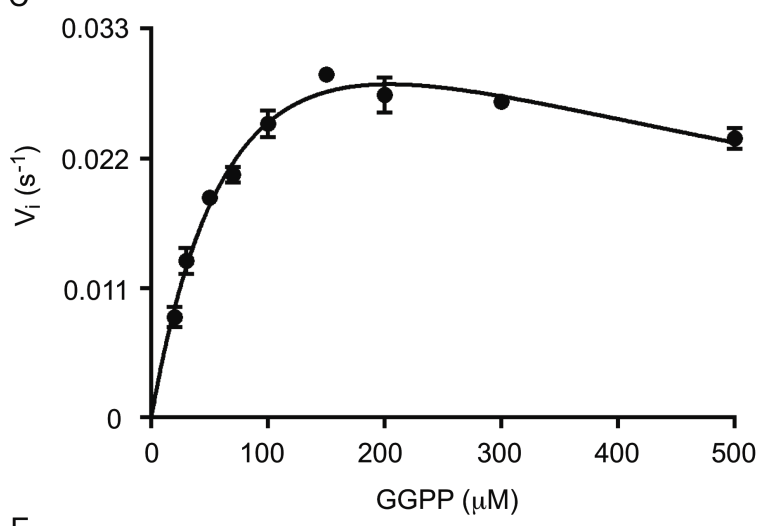

$\mathrm{E}$

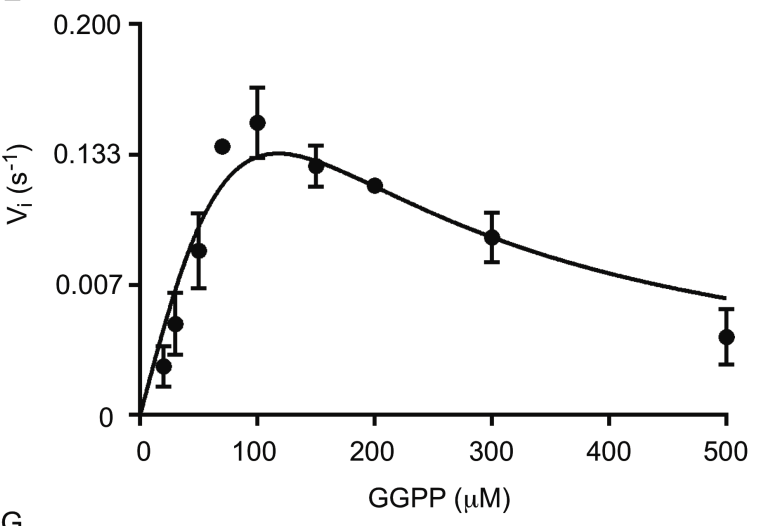

B

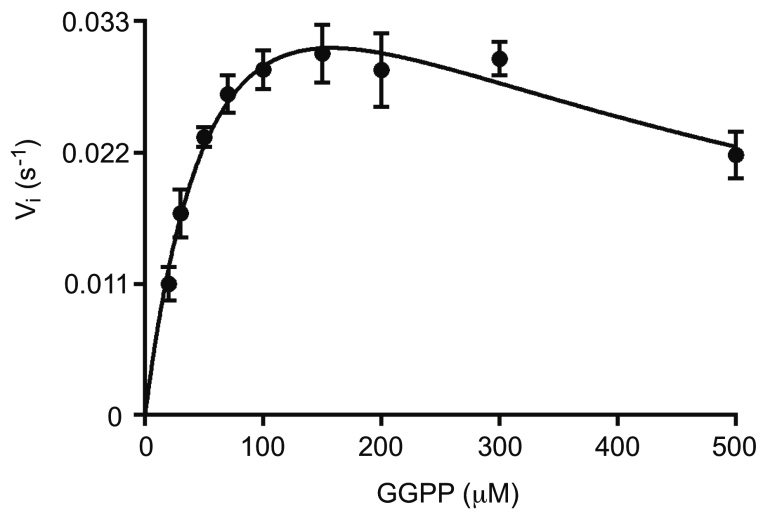

D

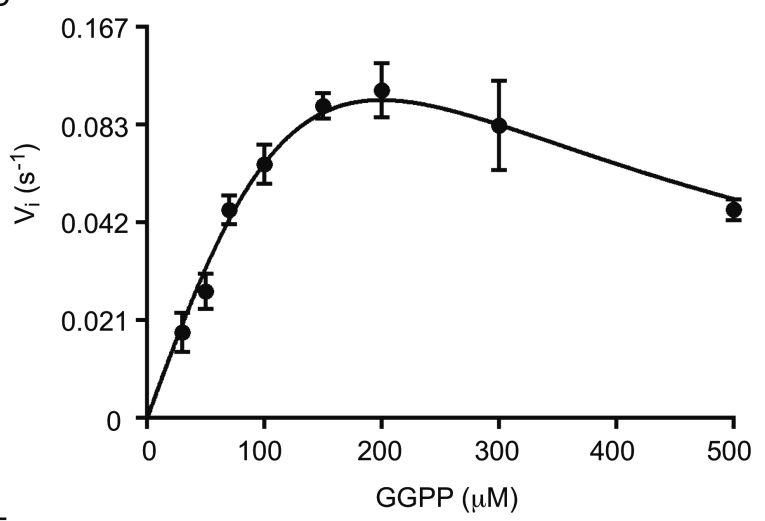

$\mathrm{F}$

$$
\begin{aligned}
& E+S \underset{\mathrm{K}_{m}}{\longrightarrow} \mathrm{E}-\mathrm{S} \longrightarrow \mathrm{E}+\mathrm{P} \\
& K_{i}{ }^{\uparrow} \downarrow \\
& \text { E-S-S } \\
& v=\frac{V m a x *[S]}{K m+[S] *\left(1+\frac{[S]}{K i}\right)}
\end{aligned}
$$

\begin{tabular}{lllll}
\hline PtmT2 Variant & $\mathrm{k}_{\mathrm{cat}}\left(\mathrm{s}^{-1}\right)^{a}$ & $\mathrm{~K}_{\mathrm{m}}(\mu \mathrm{M})$ & $\mathrm{K}_{\mathrm{i}}(\mu \mathrm{M})$ & Relative Rate $(\%)^{b}$ \\
\hline WT & $1.8 \pm 0.1$ & $44 \pm 5$ & - & 100 \\
D128A & $(4.2 \pm 0.4) \times 10^{-2}$ & $88 \pm 13$ & $206 \pm 34$ & $2.3 \pm 0.4$ \\
E133A & $(6.2 \pm 0.8) \times 10^{-2}$ & $78 \pm 17$ & $321 \pm 83$ & $3.4 \pm 0.8$ \\
D128A-E133A & $(5.6 \pm 0.5) \times 10^{-2}$ & $99 \pm 14$ & $420 \pm 79$ & $3.1 \pm 0.5$ \\
\hline
\end{tabular}

${ }^{a}$ Performed in triplicate with standard deviations listed. ${ }^{b}$ Compared to wild-type (WT) 
Figure S7. Phylogenetic analysis of PtmT2 with selected terpene synthases. Phylogenetic tree generated from the alignment of the sequences containing the $\beta \gamma$ domains of each TS from Table S4. For TSs with $\alpha \beta \gamma$ or $\alpha \beta$ architectures, the $\alpha$ domains were deleted before alignment. The tree was generated using the JTT method and the maximum likelihood algorithm using MEGA. 5.2. ${ }^{20}$ Bootstrap values $>55$ (based on 1000 resampled trials) are given at nodes. Bar, 0.5 substitutions per amino acid position. Labels indicate DTS (circles), TTS (diamonds), sesquiterpene synthase (triangle), monoterpene synthase (square), $\beta \gamma$ architecture (blue), $\alpha \beta \gamma$ architecture (red), and $\alpha \beta$ architecture (white). Shaded areas represent sequences from bacteria (peach), plant (green), and human (yellow).

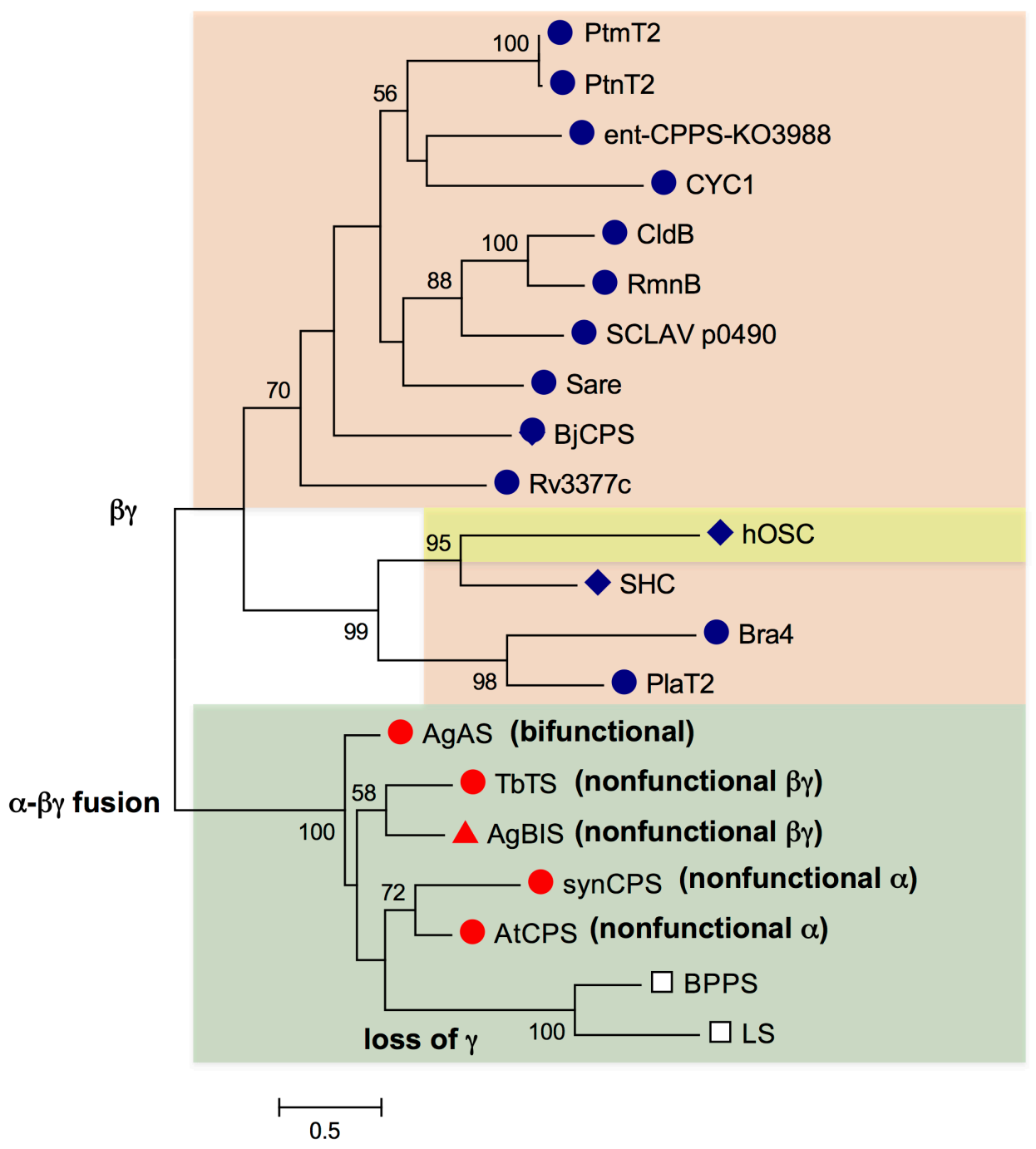


Figure S8. Electron density map for selected active site residues in PtmT2. The $2 m F_{o}-D F_{c}$ omit map for active site residues as depicted in Figure 3C with a $1.0 \sigma$ contour (pale cyan) and a $2.0 \AA$ Å carve.

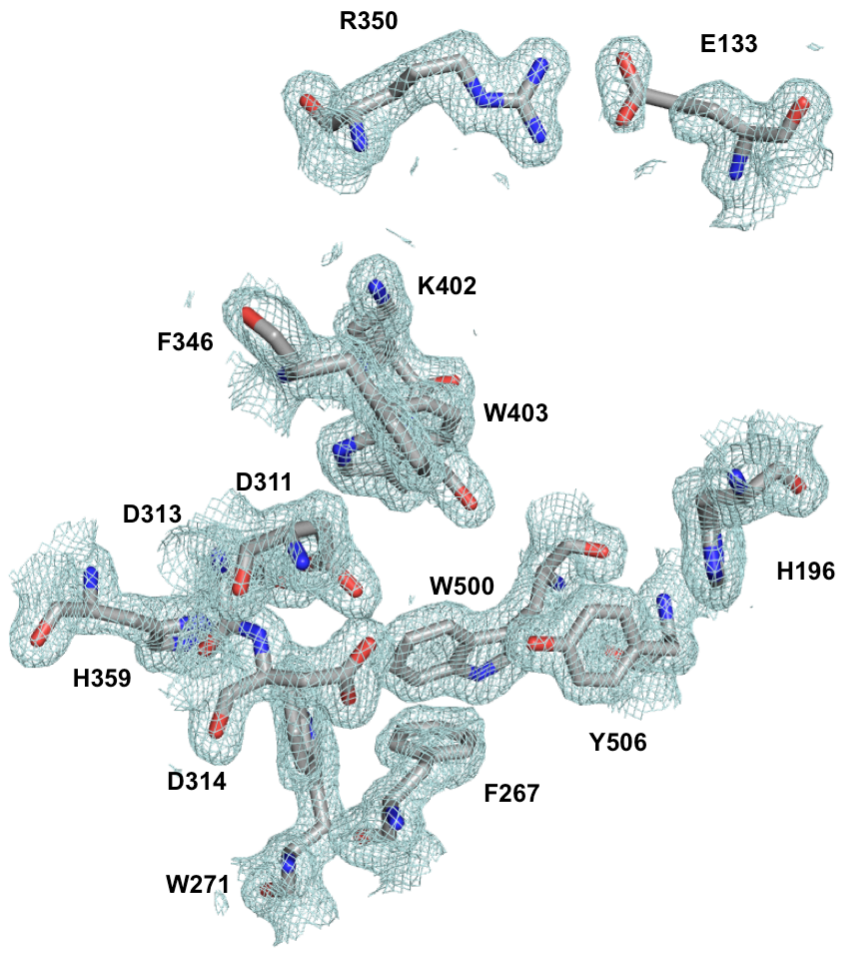




\section{Supplementary References}

(1) Roe, S. J.; Oldfield, M. F.; Geach, N.; Baxter, A. J. Labelled Compd. Radiopharm. 2013, $56,485$.

(2) Davisson, V. J.; Woodside, A. B.; Neal, T. R.; Stremler, K. E.; Muehlbacher, M.; Poulter, C. D. J. Org. Chem. 1986, 51, 4768.

(3) Hindra; Huang, T.; Yang, D.; Rudolf, J. D.; Xie, P.; Xie, G.; Teng, Q.; Lohman, J. R.; Zhu, X.; Huang, Y.; Zhao, L.-X.; Jiang, Y.; Duan, Y.; Shen, B. J. Nat. Prod. 2014, 77, 2296.

(4) Lohman, J. R.; Bingman, C. A.; Phillips, G. N.; Shen, B. Biochemistry 2013, 52, 902.

(5) Eschenfeldt William, H.; Makowska-Grzyska, M.; Stols, L.; Donnelly Mark, I.; Jedrzejczak, R.; Joachimiak, A. J. Struct. Funct. Genomics 2013, 14, 135.

(6) Koeksal, M.; Potter, K.; Peters, R. J.; Christianson, D. W. Biochim. Biophys. Acta, Gen. Subj. 2014, 1840, 184.

(7) Koeksal, M.; Hu, H.; Coates, R. C.; Peters, R., J.; Christianson, D. W. Unpublished. doi: $10.2210 / \mathrm{pdb} 3 \mathrm{pyb} / \mathrm{pdb}$.

(8) Zhou, K.; Gao, Y.; Hoy, J. A.; Mann, F. M.; Honzatko, R. B.; Peters, R. J. J. Biol. Chem. 2012, 287, 6840.

(9) Koeksal, M.; Jin, Y.-H.; Coates, R. M.; Croteau, R.; Christianson, D. W. Nature 2011, 469, 116.

(10) Reinert, D. J.; Balliano, G.; Schulz, G. E. Chem. Biol. 2004, 11, 121.

(11) Wendt, K. U.; Lenhart, A.; Schulz, G. E. J. Mol. Biol. 1999, 286, 175.

(12) Thoma, R.; Schulz-Gasch, T.; D'Arcy, B.; Benz, J.; Aebi, J.; Dehmlow, H.; Hennig, M.; Stihle, M.; Ruf, A. Nature 2004, 432, 118.

(13) McAndrew, R. P.; Peralta-Yahya, P. P.; DeGiovanni, A.; Pereira, J. H.; Hadi, M. Z.; Keasling, J. D.; Adams, P. D. Structure 2011, 19, 1876.

(14) Hyatt, D. C.; Youn, B.; Zhao, Y.; Santhamma, B.; Coates, R. M.; Croteau, R. B.; Kang, C. Proc. Natl. Acad. Sci. U. S. A. 2007, 104, 5360.

(15) Whittington, D. A.; Wise, M. L.; Urbansky, M.; Coates, R. M.; Croteau, R. B.; Christianson, D. W. Proc. Natl. Acad. Sci. U. S. A. 2002, 99, 15375.

(16) Altschul, S. F.; Gish, W.; Miller, W.; Myers, E. W.; Lipman, D. J. J. Mol. Biol. 1990, $215,403$.

(17) Krissinel, E.; Henrick, K. Acta Crystallogr., Sect. D Biol. Crystallogr. 2004, 60, 2256.

(18) Edgar, R. C. Nucleic Acids Res. 2004, 32, 1792.

(19) Gouet, P.; Courcelle, E.; Stuart, D. I.; Metoz, F. Bioinformatics 1999, 15, 305.

(20) Tamura, K.; Peterson, D.; Peterson, N.; Stecher, G.; Nei, M.; Kumar, S. Mol. Biol. Evol. 2011, 28, 2731 